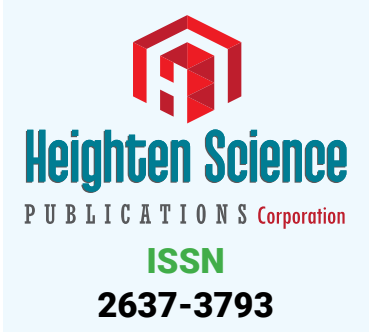

*Address for Correspondence: Walid Bai, University Hospital Center Ibn Rochd, Casablanca, Morroco, Tel: +212662336904; Email:Walid2724@gmail.com

Submitted: 25 March 2019

Approved: 04 April 2019

Published: 05 April 2019

Copyright: (c) 2019 Graiouid M, et al. This is an open access article distributed under the Creative Commons Attribution License, which permits unrestricted use, distribution, and reproduction in any medium, provided the original work is properly cited

Keywords: Kidney cancer; Radical nephrectomy; Tumor recurrence

Check for updates
Case Report

\section{Local recurrence after enlarged total nephrectomy}

\author{
Mahdi Graiouid, Walid Bai*, Messian Gallouo, Dakir \\ Mohammed, Adil Debbagh and Rachid Aboutaieb \\ University Hospital Center Ibn Rochd, Casablanca, Morroco
}

\section{Summary}

Local isolated recurrence of kidney cancer in the renal lodge after radical nephrectomy is rare and has a poor prognosis. Surgical excision, sometimes even extended to neighboring organs, is currently the only effective treatment for local recurrence of kidney cancer. The interest of new medical therapies remains to be defined. We report a case of local recurrence in a patient with radical nephrectomy.

\section{Introduction}

Kidney cancer accounts for $2 \%$ to $3 \%$ of adult cancers. Its incidence is increasing. In $80 \%$ of cases, it is renal cell carcinoma. The most important prognostic factors are histological clinical, histological subtype, Fuhrman grade, sarcomatoid contingent and tumor necrosis [1]. His prognosis remains reserved. And 30\% of cancers will evolve locally or in a metastatic mode after radical nephrectomy [2]. Local recurrences isolated after ETN for kidney cancer are rare $2 \%$ to $4 \%$, and considered to be of poor prognosis [3]. Despite its rarity, the authors agree on a systematic search for local recurrence that allows early diagnosis before the symptomatic stage. Few authors have published on this pathology; therefore, the treatment is not truly standardized. Only the interest of a heavy and maximalist surgical procedure to remove this recurrence is recognized by all the authors, at the cost of a high morbidity.

\section{Observation}

A 50-year-old woman with a history of hypertension under treatment, who had left-back lumbalgia associated with recurrent episodes of gross hematuria in 2015 leading to the diagnosis of left kidney tumor. A left radical nephrectomy is performed by a transperitoneal costal approach on November 11,2015. The histological analysis of the piece weighing $815 \mathrm{~g}$ shows a large tumor of $16 * 12 * 8 \mathrm{~cm}$ with oedematohaemorrhagic changes without necrosis related to a papillary renal cell carcinoma. The post op suites were simple and the patient was lost to follow-up.

In February 2018, 27 months after the initial radical nephrectomy, the patient consults for a curvature of the left iliac fossa. The clinical examination shows a mass of the left iliac fossa lasts polylobeb and painful to palpation (Figures 1,2).

The abdominopelvic CT scan shows a large tissue mass of the left flank and iliac fossa $10 \mathrm{~cm}$ long axis pushing back the loops and infiltrating parietal muscle structures without distant metastases (Figures 3,4). A lumpectomy was performed in monoblock carrying the muscle structures invaded the anapathological study showed a tubuloacinous and papillary carcinoma in favor of papillary renal cell carcinoma. The patient 


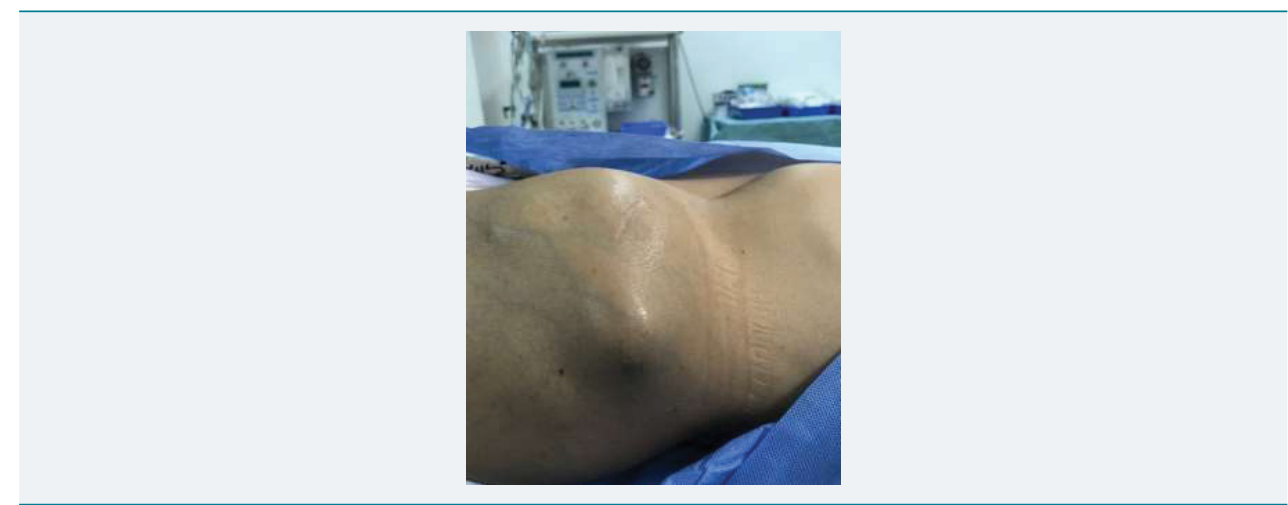

Figure 1: Clinical examination showing the mass of the iliac fossa and the flank.

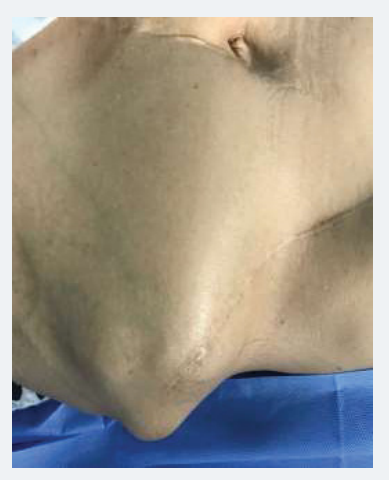

Figure 2: Clinical examination showing the mass of the iliac fossa and the flank

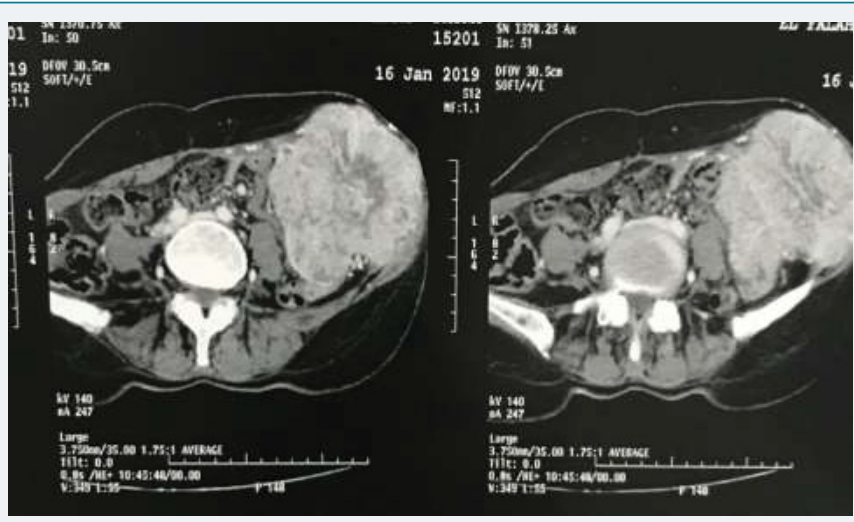

Figure 3: Cross section of abdominal pelvic CT showing tumor recurrence.

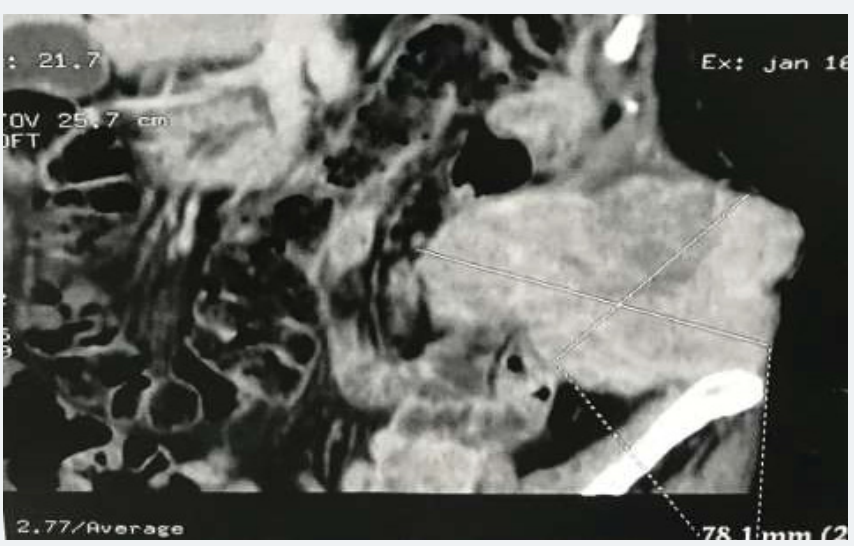

Figure 4: Frontal cut of pelvic abdominal CT showing tumor recurrence. 
was reviewed in consultation with a good evolution. The last thoraco-abdominopelvic CT scan performed 12 months after the local recurrence surgery did not show either local recurrence or distant metastases.

\section{Discussion}

At diagnosis, $40 \%$ of renal tumors are localized, $20 \%$ of patients have tumors of large volume, 15 to $30 \%$ are immediately metastatic with multiple localizations in the majority of cases [4].

A high incidence of local recurrence is found in T3-T4 stages (capsular intrusion). They can occur at any initial stage of the tumor but it is more rare with the lowest stages (T1-T2).

The risk of local recurrence was evaluated at $2 \%$ of cases after resection surgery for T1-3 N0M0 kidney cancer with a median time of 26 to 47 months. More than 95\% of recurrences occur in the first 5 years of follow-up [5]. It may result from incomplete excision of cancerous tissue, persistence of affected regional lymph nodes or venous tumor thrombi [5]. In one study, reporting 230 ETN open-air results, tumor size, TNM tumor stage, Führman's nuclear grade, histological type of cancer and the existence of symptoms or telltale signs were correlated with the rate of survival without recurrence [6].

Early diagnosis of local recurrence is necessary because surgical excision is the best treatment.

In the main studies, it should be noted the frequent discovery of asymptomatic recurrences that will be detected by means of imaging $[7,8]$.

The symptomatic forms can result in abdominal or flank pain, gross hematuria, wall curvature, lumbar mass, fever, anemia, weight loss, dyspnea or general impairment. The percentage of symptoms varies from one series to another from $7 \%$ to $82 \%$ [9]. In general, the symptoms are present in $1 / 3$ of the cases and are not specific.

Spiral scanner is the ideal modality for conducting postoperative monitoring in patients at high risk of recurrence or metastatic spread. Particular attention should be paid when performing CT exams taking into account the particular aspects of this cancer, in its typical forms and atypical manifestations of recurrence [10]. Local recurrence can result in a mass of tissue density, rounded, well-defined or irregular with polylobed polycyclic contours, enhancing after injection of the contrast medium. This mass can be bulky invading the abdominal wall, diaphragm and large vessels. It may also appear as a small mass of tissue density in the nephrectomy box causing the diagnosis of fibrosis to be discussed.

The local recurrence isolated after ETN posed a problem of therapeutic decision because it represents in itself a high risk of openly developing metastatic disease [5]. The surgical procedure must be maximal, taking away any visible lesion and sacrificing the neighboring organs who would be affected: colon, spleen, hepatic segments, tail of the pancreas, adrenal, psoas muscles, squares of the loins or diaphragmatic It is a heavy surgical procedure AND the complete excision of the whole lesion cannot be carried out in all the cases; especially when there is infiltration of the wall of large blood vessels.

Other therapeutic strategies have been used in combination with surgery: systemic therapy (hormone therapy, immunotherapy, chemotherapy immunochemotherapy ...), intraoperative radiotherapy and external radiotherapy postoperatively as an adjunct to surgery. All these treatments did not significantly improve the survival rate [7]. 


\section{Conclusion}

Local isolated recurrence of renal cell carcinoma after enlarged total nephrectomy is rare with varying incidence from one series to another. Few authors have published on this pathology; therefore, the treatment is not truly standardized. It remains a poor prognosis.

\section{References}

1. Jemal A, Ward E, Hao Y, Xu J, Murray T, et al. Cancer statistics. 2008. CA Cancer J Clin. 2008; 58 : 71-96. Ref.: https://tinyurl.com/y2jhxng4

2. Zisman A, Pantuck AJ, Wieder J, Chao DH, Dorey F, et al. Risk group assessment and clinical outcome algorithm to predict the natural history of patients with surgically resected renal cell carcinoma. $J$ Clin Oncol. 2002; 20: 4559-4566. Ref.: https://tinyurl.com/y43tkkdo

3. Schrödter S, Hakenberg OW, Manseck A, Leike S, Wirth MP. Outcome of surgical treatment of isolated local recurrence after radical nephrectomy for renal cell carcinoma. J Urol. 2002; 167: 1630-1633. Ref.: https://tinyurl.com/y2dj239y

4. Coulange C, Rambeaud JJ. Cancer du rein de l'adulte: histoire naturelle. Rapport Congrès AFU 1997 Prog Urol. 1997; 7: 763-765.

5. Master VA, Gottschalk AR, Kane C, Carroll PR. Management of isolated renal fossa recurrence following radical nephrectomy. J Urol 2005; 174: 473-477. Ref.: https://tinyurl.com/y6opjrsg

6. Peyromaure M, Barry Delongchamps N, Roffi F, Debre B, Zerbib M. Résultats de la néphrectomie élargie à ciel ouvert : à propos d'une série de 230 patients. Prog Urol. 2005; 15: 18-22. Ref.: https://tinyurl.com/y4bg2b32

7. Gogus C, Baltaci S, Beduk Y, Sahinli S, Kupeli S, et al. Isolated local recurrence of renal cell carcinoma after radical nephrectomy: experience with 10 cases. Urology. 2003; 61: 926-929. Ref.: https://tinyurl.com/y4kmqy8w

8. Patard JJ, Baumert H, Bensalah K, Bernhard JC, Bigot P, et al. [CCAFU Recommendations 2013: Renal cancer]. Prog Urol. 2013; 23(suppl 2): S177-S204. Ref.: https://tinyurl.com/y3898gne

9. Gaurav Bandi C, Charles Wen, Timothy D Moon, Stephen Y Nakada. Single Center Preliminary Experience with Hand-Assisted Laparoscopic Resection of Isolated Renal Cell Carcinoma Fossa Recurrences. Urology. 2008; 71: 495-499. Ref.: https://tinyurl.com/y4rm9dw6

10. Vogl UM, Zehetgruber H, Dominkus $M$, Hejna $M$, Zielinski CC, et al. Prognostic factors in metastatic renal cell carcinoma: metastasectomy as independent prognostic variable. $\mathrm{Br} \mathrm{J}$ Cancer. 2006; 95: 691-698. Ref.: https://tinyurl.com/y67nwdfh 